\title{
Surgery in the Acute Phase of Infective Endocarditis: 5 Years after Our Initial Experience
}

\author{
Youssef El Bekkali ${ }^{1}$, Noureddine Atmani ${ }^{*}$, Siham Bellouize ${ }^{1}$, Mohamed Drissi², \\ Younes Moutakiallah'1, Mehdi Bamous ${ }^{1}$, Abdessamad Abdou', Fouad Nya', \\ Anis Seghrouchni', Mahdi Aithoussa', Brahim Amahzoune1, \\ Abdedaim Hatim Ghadbane ${ }^{2}$, Abdelatif Boulahya ${ }^{1}$ \\ ${ }^{1}$ Cardiac Surgery Department, Mohammed V Military Hospital, Rabat, Morocco \\ ${ }^{2}$ Reanimation of Cardiac Surgery Department, Mohamed V Medical Faculty, Rabat, Morocco \\ Email: *dratmani@hotmail.fr
}

Received 26 May 2016; accepted 16 August 2016; published 19 August 2016

Copyright (C) 2016 by authors and Scientific Research Publishing Inc.

This work is licensed under the Creative Commons Attribution International License (CC BY). http://creativecommons.org/licenses/by/4.0/

(c) () Open Access

\begin{abstract}
Aim: Comparing the results of acute phase infectious endocarditis surgery between two periods. Methods and Results: The study is about 2 series, series $A$ between 1993 and 1997, and series B between 1998 and 2012, respectively 13 and 51 patients. The two periods were similar concerning the number of patients per year, which was 3.12 cases/year for series $A$ and 3.64 cases/year for series $B$. The authors noted a change in epidemiological profile, with an increase of median age (31 y.o for series A and 37 y.o for series B), and the emergency of endocarditis on prosthetic valve (none on series A and 8 cases for series B). Surgical indications and results didn't change too much, hospital mortality rate was $15.3 \%$ for series $A$ and $17.6 \%$ for series $B$. Conclusion: Infectious endocarditis is still a major public healthcare problem in developing countries, despite the development of diagnostic tools and patient care. Prevention is still the major asset in the treatment of this disease.
\end{abstract}

\section{Keywords}

Infectious Endocarditis, Acute Phase, Surgery

\section{Introduction}

Valvular surgery performed during the active phase of infective endocarditis (IE) is indicated in an increasing

*Corresponding author.

How to cite this paper: El Bekkali, Y., Atmani, N., Bellouize, S., Drissi, M., Moutakiallah, Y., Bamous, M., Abdou, A., Nya, F., Seghrouchni, A., Aithoussa, M., Amahzoune, B., Ghadbane, A.H. and Boulahya, A. (2016) Surgery in the Acute Phase of Infective Endocarditis: 5 Years after Our Initial Experience. World Journal of Cardiovascular Diseases, 6, 275-284.

http://dx.doi.org/10.4236/wjcd.2016.68031 
proportion of patients and currently ranges from 30\% to $60 \%$. Recent changes in the epidemiological and microbiological profile of the disease could explain this trend, with an increase in complicated situations due to a greater incidence of more virulent microorganisms and intracardiac material infections. Several works have determined the prognosis of patients who underwent surgery before the end of antimicrobial therapy; most showed that the advent of surgical therapy for complicated IE has been associated with reduced mortality. Thus, these results have encouraged physicians to offer surgical treatment for an increasing number of patients. Although the indications for surgery are well defined in international guidelines, no consensus exists on the optimal timing of surgical intervention because of a lack of evidence-based data. However, in patients with the most severe complications, surgery cannot be delayed and must be performed as soon as possible, frequently before the end of the first week of antimicrobial therapy. This very early surgical management, which can improve prognosis, raises the concern of the theoretical risk of both high operative mortality and recurrence or postoperative valve dysfunction (PVD) by implanting material into infected tissues. The aim of our work is to make a comparison between two periods of acute phase infective endocarditis surgery operated in the Department of Cardiovascular Surgery, Mohammed V Military Hospital, Rabat—Morocco.

\section{Materiel and Methods}

This was a single center retrospective study conducted over two periods:

The first period runs from September 1993 to December 1997 [1]. (Series A) and 13 cases were included with an average of 3.12 patients/year, which reflected the initial experience of the department.

The second period runs from January 1998 to December 2012. (Series B) and 51 cases were included with an average of 3.64 patients/year.

Identification of patients was done from patients records, the diagnosis of infective endocarditis was established according to Duke criteria. All patients in this study group had surgery and were followed postoperatively for a period of 1 month. These medical records were reviewed to identify demographic, clinical, microbiological, operative and postoperative data.

All variables were entered to database using Microsoft excel and expressed as mean and/or percentage.

\section{Results}

Although there is a difference between the number of patients and duration of both studies, the number of patients/year is substantially the same which allows us to make this comparison.

\subsection{Distribution by Average Age (Table 1)}

The average age of both series is respectively 31 and 37 y.o:

- Series (A): 31 (9 - 42 y.o);

- Series (B): 37 (9 - 60 y.o).

\subsection{Distribution by Sex (Table 1)}

There were exclusively males in the first period, while in the second, the fifth of the patients were females.

- Series (A): 100\% Male;

- Series (B): 78.4\% Male and 21.6\% Female.

\subsection{Initial Valvular Disease (on Clinical Findings and Echocardiogram) (Table 1)}

In the first period, the valvular lesions were all rheumatic, while in the second period, we had some cases of prosthetic valvular endocarditis (8\%).

\subsection{Preoperative Clinical State (Table 1)}

More than three quarters of patients in both series were symptomatic (NYHA III, IV) with signs of left or global heart failure. 
Table 1. Demographic and clinical characteristic.

\begin{tabular}{|c|c|c|}
\hline & Series $A(n=13)$ & Series $B(n=51)$ \\
\hline Age (years) & $31(9-42)$ & $37(9-60)$ \\
\hline \multicolumn{3}{|l|}{ Sex } \\
\hline - Male & $100 \%$ & $78.4 \%$ \\
\hline - Female & $0 \%$ & $21.6 \%$ \\
\hline \multicolumn{3}{|l|}{ Etiology } \\
\hline - Rheumatic & (12) $92 \%$ & (43) $84 \%$ \\
\hline - Bicuspid AV & (1) $8 \%$ & (4) $8 \%$ \\
\hline - Prosthesis & $0 \%$ & (4) $8 \%$ \\
\hline Fever: & $100 \%$ & $81.1 \%$ \\
\hline \multicolumn{3}{|l|}{ NYHA: } \\
\hline - Class I & 0 & $1(5 \%)$ \\
\hline - Class II & $1(7.6 \%)$ & $15(30 \%)$ \\
\hline - Class III & $8(61.5 \%)$ & 18 (36\%) \\
\hline - Class IV & $4(30.7 \%)$ & $15(30 \%)$ \\
\hline \multicolumn{3}{|l|}{ Neurologic signs: } \\
\hline - Ischemic Stroke & $2(15 \%)$ & $4(7.8 \%)$ \\
\hline - Hemorrhagic stroke & $0 \%$ & $1(1.9 \%)$ \\
\hline \multicolumn{3}{|l|}{ ECG: } \\
\hline - Sinus Rhythm & 11 & 46 \\
\hline - Atrial Fibrillation & 2 & 5 \\
\hline Chest radiograph: CTR & $0.58(0.55-0.70)$ & $0.56(0.55-0.68)$ \\
\hline
\end{tabular}

\subsection{Echocardiographic Data}

The echocardiographic findings are summarized in Table 2.

On both series, we noted a predominance of regurgitation lesions, but in the second series, there were some cases of prosthetic valvular endocarditis and on mitral valve alone.

\subsection{The Therapeutic Management (Table 3)}

a) Antibiotics

All patients were under antibiotic treatment on admission including IV amoxicillin (200 mg/kg) and IV gentamicin ( $3 \mathrm{mg} / \mathrm{kg}$ ) right after clinical suspicion. The treatment is then guided according to the clinical findings and the past medical history of each patient. The average duration of the preoperative antibiotic therapy was 23 days for the series $\mathrm{A}$ and 20 days for series $\mathrm{B}$.

b) Bacteriologic Data

The alleged entry door was usually dental or ENT.

Blood cultures were in $46 \%$ of cases negative for series A and $66 \%$ negative for series B.

The bacterial agents found were mainly streptococcus and staphylococcus in series A, while in the series B we noticed the emergence of Klebsiella pneumoniae and Enterobacter cloacae.

c) Valve/Prosthesis Culture (Table 3)

In the Infective endocarditis with negative blood cultures, the culture of the valve or prosthesis isolated the 
Table 2. Echocardiography data.

\begin{tabular}{lcc}
\hline & Series A $(\mathrm{n}=13)$ & Series B $(\mathrm{n}=51)$ \\
\hline Vegetations & 6 & 30 \\
- Aortic & 1 & 12 \\
- Mitral & 4 & 05 \\
- Mitro-aortic & 0 & 04 \\
- Prosthesis & 1 & 05 \\
Ruptured Chord & 2 & 10 \\
Aortic annulus abscess & 02 & 14 \\
Valvular perforation & & \\
LV function & $56 \%$ & $54 \%$ \\
- EF & 0 & $40 \%$ \\
- EF $<40 \%$ & $65 \pm 7$ & $63 \pm 10$ \\
- LVTDD & & \\
Site of lesions & 4 & 15 \\
- Aortic regurgitation (AR) & 0 & 5 \\
- Mitral regurgitation (MR) & 1 & 12 \\
- AR + MR & 2 & 2 \\
- AR + Mitral Disease & 0 & 9 \\
- AR + MR + TR & & \\
- Prosthesis & & \\
\hline
\end{tabular}

Table 3. bacteriological data.

\begin{tabular}{lcc}
\hline & Series A $(\mathrm{n}=13)$ & Series B $(\mathrm{n}=51)$ \\
\hline Mode of Entry & 06 & 04 \\
- Dental & 01 & 05 \\
- ENT & 01 & 03 \\
- Skin & 0 & 01 \\
- Pelvis & & \\
Blood cultures & 07 & 17 \\
- Positive & $06(46 \%)$ & $34(66 \%)$ \\
- Negative & & \\
Bacteria & 04 & 08 \\
- Streptococcus & 03 & 07 \\
- Staphylococcus & 0 & 01 \\
- Enterobacter cloacae & 0 & 01 \\
- Klebsiella pneumoniae & 2 & 6 \\
Positive valve culture & 2 & 3 \\
- Streptococcus & 0 & 3 \\
- Staphylococcus & 0 & 2 \\
Positive prosthesis culture & 0 & 1 \\
- Staphylococcus & 0 & \\
- Enterobacter & & \\
\hline
\end{tabular}


responsible bacteria in 2 cases (6.33\%) of the first series, and in 6 cases (34\%) of the second one.

d) Heart Failure Treatment

The symptomatic post operative treatment of heart failure was prescribed for 8 patients (61.5\%) for the series A and 31 patients for the series B (60.7\%).

e) Surgical Treatment (Table 4)

The surgery was performed by median sternotomy, cardiopulmonary bypass was installed. Myocardial protection was performed by moderated hypothermia and cold cardioplegic solution.

Closing annular abscess: in fact the patient was having annular cover spontaneously evacuated, and it was sutured by single patched stitches before the introduction of the prosthesis.

Hospital mortality (1 month) was 15.3\% (2/13) for Series A and 17\% (9/51) for series B. The causes of death are summarized in Table 5 .

Table 4. Operative data.

\begin{tabular}{lcc}
\hline & Series A & Series B \\
\hline Indications & & 31 \\
- Haemodynamic reasons & 13 & 14 \\
- High emboli risk & 0 & 2 \\
- Uncontrolled infectious syndrome & & \\
Surgical interventions & 0 & 5 \\
- MVR & 4 & 25 \\
- AVR & 9 & 16 \\
- AVR+MVR & 0 & 4 \\
- Prosthesis change & 2 & 8 \\
- Tricuspid valve Repair & 2 & 108 (35 - 200) \\
- Annular abcess closure & $100(40-180)$ & $74(50-150)$ \\
CPB Average time (min) & $69(45-140)$ & 38 \\
Aortic clumping time (min) & 7 & \\
Vasoactive drugs & &
\end{tabular}

Table 5. Mortality and morbidity.

\begin{tabular}{lcc}
\hline & Series A $(\mathrm{n}=13)$ & Series B $(\mathrm{n}=51)$ \\
\hline Hospital mortality & $15.3 \%$ & $17 \%$ \\
Average ICU time (days) & $02(1-10)$ & $03(1-17)$ \\
Low Flow & $06(46 \%)$ & $16(31 \%)$ \\
Arrythmia & 04 & 17 \\
Conduction disorder & 01 & 04 \\
Lung Disease & 01 & 03 \\
Post operative bleeding $(\mathrm{ml})$ & $550(200-1500)$ & 10 \\
Transfusion & 3 & 04 \\
Cardiogenic shock & 0 & 02 \\
Septic shock & 01 & 01 \\
Tamponnade & 01 & 02 \\
Prosthesis disinsertion & 0 & $1800)$ \\
\hline
\end{tabular}




\section{Discussion}

Long ago, the epidemiological profile of infective endocarditis in undeveloped countries like Morocco, was characterized by the young age, the incidence of rheumatic lesions favoring bacterial transplantation and the prevalence of Streptococcus.

But comparing the two series has enabled us to identify three epidemiological changes.

- The average age has increased by 5 years, from 32 y.o to 37 y.o, which is due to the improving of life expectancy in Morocco, that rose from 69 y.o in 2000 to 76 y.o in 2012. But it remains largely lower than what's known in reviews [1]-[3] and this is explained by the remaining of rheumatic lesions in our country mainly affecting young adults.

- We also noticed the female's appearence in the second series with a proportion of $21 \%$ which is lower than what's known in reviews 30\% [1]-[3] the predominance of male patients in both series is due to our patient's recruitment which is predominantly military.

- The incidence of rheumatic valvular heart disease remains largely dominant but we noted the emergence of prosthetic valve endocarditis with a proportion of $8 \%$ lower than reviews (21\%) [4], probably also because of our recruitment in a specific population (military), on the other hand our practice has started in 1993, before that, the patients were operated in France.

But these series are still totally different from what is currently observed in Europe or the USA. In these countries the age of onset is late and rheumatic endocarditis lesions have almost disappeared, the main cause in these countries is degenerative lesions and valvular prosthesis [1]-[3].

Clinically we noted two points:

- The Appearance of IE on native mitral valve isolated with a proportion of $12 \%$ which is still lower than the data in the Reviews which is around 26\% [5] this is due to the fact that our series is exclusively surgical.

- The very high incidence of heart failure noted in both series. All patients have valvular lesions or prosthesis, with fever and more than $3 / 4$ of the patients were symptomatic (II, III, IV NYHA) which suggests the diagnosis (based on clinical findings, blood cultures and echocardiography).

The association of new onset heart failure with fever must make the diagnosis of IE highly probable [6]. Heart failure usually occurs more frequently in aortic lesions (29\%) than mitral (20\%) or tricuspid (8\%) [7], and may happen acutely (by perforation) or insidiously (consequence of old valvular lesions decompensated by EI) and that is the case for the majority of our patients as evidenced by symptoms and cardiomegaly on chest radiograph with the average CTR $>0.55$ and LV dilation on echocardiography $>64 \mathrm{~mm}$ on both series.

Neurological complications are second to heart failure and occur in $30 \%$ to $40 \%$ of cases. This is due to vegetation's migration causing an ischemic stroke, or hemorrhagic stroke by the convertion of a white infarction, or mycotic aneurysm rupture [8] [9]. The percentage of strokes was 15\% for A series and 9.8\% for B series, which is still very low compared with reviews, probably due to that the two series are purely surgical.

The diagnosis of IE is clinically suspected in the presence of a fever and cardiovascular examination findings (regurgitation heart murmur) and confirmed by echocardiographic examination showing evocative pictures (vegetation, abscess).

Concerning native valve vegetation, transthoracic echocardiogram had a sensitivity rate of 0.8 and this rate reaches 0.92 in Transoesophageal echocardiogram [10]. Yet the diagnosis remains unclear if there are calcifications or prosthesis [11]. It is commonly known that large vegetations (more than $1 \mathrm{~cm}$ ) [12].

The comparison of echocardiographic data allowed us to note that aortic disease is the most frequent followed by mitro-aortic lesions and then mitral prosthesis, contrary to reviews in which we note the predominance of aortic lesions, then mitral, prosthesis, and mitroaortic at last [2] [13]-[15], this is because the underlying disease for the majority of our patients is rheumatic disease, often multivalvular.

Bacteriologically, we unfortunately noted a very high percentage of negative blood cultures (46\%) for Series A and (66\%) for Series B compared with the data of Western reviews that doesn't exceed 10\% [5] but is close to the North African reviews (47.3\%) [16]. This can be explained by the systematic prescription of antibiotics to treat a fever or insufficient laboratories.

Indeed, in case of a negative blood culture the following possibilities should be discussed.

$\rightarrow$ The conditions of the blood samples: time, number, and volume components of critical conditions;

$\rightarrow$ Prior antibiotics;

$\rightarrow$ Endocarditis related germs. 
- Slow growth requiring prolonged group culture HAECK

- intracellular development coxiella, bartonella...

- Yeast

Removed valves/prosthesis culture allowed a mild raise of the number of germs which were identified by positive blood culture, dominated by streptococci and staphylococci which joins the data in the reviews [2] [17]. But we also noted Enterobacteria in the B series.

Since the 80s the development of cardiac surgery and the progress in medical investigations has contributed to the reduction of IE mortality when is operated in the active phase, and to identify its indications. Indeed, these data are hemodynamic status, biological and Embolic disorders [18]-[20].

Early surgery in the active phase avoids progressive heart failure, irreversible structural damage and systemic embolism [7] [21] [22]. The most dangerous complication otherwise is a persistent or recurrent endocarditis which is not influenced by the duration of pre-operative antibiotics treatment [23]-[25] on the one hand and on the other hand the risk is controversial, important for some [26] [27] and significant for others [24] [28] [29].

Comparing the surgical indications in both series, we found that the hemodynamic indications were exclusive to the A Series and largely dominant in the B series that joins data from the reviews. But we especially noted the appearance in the B series of other indications such as embolic risk and uncontrolled infection.

Heart failure was the main operative indication in the active phase since the mortality of IE on native valve in case of heart failure is 55\% - 80\% without surgery, decreasing to $10 \%$ - 35\% with surgery. But this rate is dependent on two factors: Dyspnea stage and the time between the installation of the heart failure and surgery, the less the period is, better are the results [30] [31].

The embolic risk increased especially in case of vegetation with a diameter $>10 \mathrm{~mm}$ or highly mobile [9] [12] [32] or related to certain microorganisms (Staphylococcus, Streptococcus bovis, candida). This indication usually occupies the 3rd place in the surgical indication chart in the active phase, and is in the 2nd place in our series $27 \%$ which is due to the fact that the majority of our patients have polyvalvular lesions.

The none-control of the infection is usually the second indication, we noted it in $4 \%$ of our patients, in which we count the persistent infection, 7 to 10 days of antibiotics or due to infection by resistant microorganisms. It must be done as quickly as possible because there is a high risk of fistulas, abscesses and pseudo aneurysm [7] [33].

The problem for the surgical indication in case of a stroke should be discussed case by case. It seems that if the risk of hemorrhagic transformation is reliable to $20 \%$ if the patient is operated before 72 hours, the risk increases to $50 \%$ between 4 and 14 days, then it returns to nearly zero after the 4 th week. But the risks of worsening are considerable in the first four weeks in case of cerebral bleeding [34]. Thus the period of at least 3 - 4 weeks should elapse before surgery if the patient's condition is stable.

The main goal of surgery for infective endocarditis is to eradicate infected tissues and to restore the valvular structure either by valve repair (especially for mitral or tricuspid), homograft or prosthesis [35] [36].

In both series no cases of mitral valve repair could be made, given the importance of rheumatic alterations of the valve. Due to the young age of our patients we chose mechanical valve replacement. As for homograft valves are not yet used in our country.

The mortality rate in the two series is essentially the same $(15.3 \%, 17 \%)$ which is comparable to a Tunisian series (13\%) [16]. Tunisia is a country like ours with the same epidemiological characteristics. But seems higher compared to that of Western series [37] [38], this is due to the fact that the majority of our patients were at an advanced stage of their valvular disease as evidenced by their functional status (more than $70 \%$ in stage III, NYHA IV).

It is proven that the prognosis of IE operated at a stage II NYHA dyspnea is more favorable than stage III, IV [37]-[39]. This highlights the importance of surveillance and prophylaxis of patients with valvular prosthesis to avoid an endocarditis darkening the prognosis.

Currently, the long term prognosis of operated EI patients is good with a mortality rate 36\% patient-years [40] [41] and 5-year survival is up to $60 \%$ to $90 \%$ depending on type of endocarditis, on native or prosthetic valve type, and surgery (repair or replacement) [42] [43].

Despite the retrospective nature of the study and small number of patients included, this study permitted us to better understand the management of these patients with this condition.

\section{Conclusions}

10 years since the publication of our very first series on infectious endocarditis, the disease is still relevant 
whether on native or prosthetic valve. It is characterized in our country on the one hand by the young age of onset and on the other, by the predominance of rheumatic lesions often advanced, precipitating the worsening of the hemodynamic status.

This context makes the indication for surgery in the active phase often legitimate before the onset of myocardial degeneration.

But despite the very encouraging progress in surgery, prophylactic measures should not, however, be overshadowed.

\section{References}

[1] el Bekkali, Y., Boulahya, A., Wahid, F., Aouifi, A., Amehzoune, B., Salkane, C., Arji, M. and el Kirat, M. (2001) Surgery of Active-Phase Infective Endocarditis: Report of 13 Cases. Annales de Cardiologie et d'Angéiologie (Paris), 50, 269-273. http://dx.doi.org/10.1016/S0003-3928(01)00031-2

[2] Delahaye, F., Goulet, V., Lacassin, F., Ecochard, R., Selton-Suty, C., Hoen, B., et al. (1995) Characteristics of Infective Endocarditis in France in 1991. A 1-Year Survey. European Heart Journal, 16, 394-401.

[3] Goulet, V., Etienne, J., Fleurette, J. and Netter, R. (1986) Caracteristiques epidemiologiques de l'endocardite infectieuse en France. La Presse Médicale, 14, 1855-1858.

[4] Selton-Suty, C., Iung, B., Bernard, Y., Donal, E., Nazerollas, P., Sportouch-Dukhan, C., et al. (2010) Continuing Changing Profile of Infective Endocarditis: Results of a Repeat One-Year Population-Based Survey in France in 2008. European Heart Journal, 31, 467.

[5] Delahaye, J.P., Loire, R., Delahaye, F. and Vandenesch, H.B. (2000) Endocardites infectieuses. Encycl Méd Chir. Cardiologie, 11-013-B-10, 25 p.

[6] McKinsey, D.S., Ratts, T.E. and Bisno, A.L. (1987) Underlying Cardiac Lesions in Adults with Infective Endocarditis. The Changing Spectrum. The American Journal of Medicine, 82, 681-688. http://dx.doi.org/10.1016/0002-9343(87)90001-5

[7] Baddour, L.M., Wilson, W.R., Bayer, A.S., Fowler Jr., V.G., Bolger, A.F., Levison, M.E., et al. (2005) Infective Endocarditis: Diagnosis, Antimicrobial Therapy, and Management of Complications: A Statement for Healthcare Professionals From the Committee on Rheumatic Fever, Endocarditis, and Kawasaki Disease, Council on Cardiovascular Disease in the Young, and the Councils on Clinical Cardiology, Stroke, and Cardiovascular Surgery and Anesthesia, American Heart Association: Endorsed by the Infectious Diseases Society of America. Circulation, 111, e394-e434. http://dx.doi.org/10.1161/CIRCULATIONAHA.105.165564

[8] Thuny, F., Avierinos, J.-F., Tribouilloy, C., Giorgi, R., Casalta, J.-P., Milandre, L., et al. (2007) Impact of Cerebrovascular Complications on Mortality and Neurologic Outcome during Infective Endocarditis: A Prospective Multicentre Study. European Heart Journal, 28, 1155-1161. http://dx.doi.org/10.1093/eurheartj/ehm005

[9] Cabell, C.H., Pond, K.K., Peterson, G.E., Durack, D.T., Corey, G.R., Anderson, D.J., et al. (2001) The Risk of Stroke and Death in Patients with Aortic and Mitral Valve Endocarditis. American Heart Journal, 142, 75-80. http://dx.doi.org/10.1067/mhj.2001.115790

[10] Jacob, S. and Tong, A. (2002) Role of Echocardiography in the Diagnosis and Management of Infective Endocarditis. Current Opinion in Cardiology, 17, 478-485. http://dx.doi.org/10.1097/00001573-200209000-00006

[11] Habib, G. (2003) Apport de l'échographie dans l'endocardite infectieuse. Archive des maladies du cœur et des vaisseaux. Tome 96 spécial V, Juin 2003.

[12] Thuny, F., Di Salvo, G., Belliard, O., Avierinos, J.F., Pergola, V., Rosenberg, V., et al. (2005) Risk of Embolism and Death in Infective Endocarditis: Prognostic Value of Echocardiography: A Prospective Multicenter Study. Circulation, 112, 69-75. http://dx.doi.org/10.1161/CIRCULATIONAHA.104.493155

[13] Karalis, D.G., Bansal, R.C., Hauck, A.J., Ross Jr., J.J., Applegate, P.M. and Jutzy, K.R. (1992) Transesophageal Echocardiographic Recognition of Subaortic Complications in Aortic Valve Endocarditis. Clinical and Surgical Implications. Circulation, 86, 353-362. http://dx.doi.org/10.1161/01.CIR.86.2.353

[14] Tleyjeh, I.M., Abdel-Latif, A., Rahbi, H., Scott, C.G., Bailey, K.R., Steckelberg, J.M., et al. (2007) A Systematic Review of Population-Based Studies of Infective Endocarditis. Chest, 132, 1025-1035. http://dx.doi.org/10.1378/chest.06-2048

[15] Horscotte, D. (1991) Prosthetic Valve Endocarditis. IRCC Publichers, London, 229-261.

[16] Tarmiz, A., Jebri, S., et al. (2010) Chirurgie de l'endocardite sur valves natives à la phase active. Annales de Cardilogie et d'Angéiologie, 59, 8-13.

[17] Van der Meer, J.T., van Vianen, W., Hu, E., van Leeuwen, W.B., Valkenburg, H.A., Thompson, J. and Michel, M.F. (1991) Distribution, Antibiotic Susceptibility and Tolerance of Bacterial Isolates in Culture-Positive Cases of Endocarditis 
in The Netherlands. European Journal of Clinical Microbiology and Infectious Diseases, 10, 728-734. http://dx.doi.org/10.1007/BF01972497

[18] Tornos, P., Iung, B., Permanyer-Miralda, G., Baron, G., Delahaye, F., Gohlke-Bärwolf, Ch., et al. (2005) Infective Endocarditis in Europe: Lessons from the Euro Heart Survey. Heart, 91, 571-575. http://dx.doi.org/10.1136/hrt.2003.032128

[19] Olaison, L. and Pettersson, G. (2003) Current Best Practices and Guidelines. Indications for Surgical Intervention in Infective Endocarditis. Cardiology Clinics, 21, 235-251. http://dx.doi.org/10.1016/S0733-8651(03)00029-8

[20] (2005) Recommandations de la Société française de cardiologie concernant la prise en charge des valvulopathies acquises et des dysfonctions de prothèse valvulaire. Archives des Maladies du Cœur et des Vaisseaux, 98.

[21] Hasbun, R., Vikram, H.R., Barakat, L.A., Buenconsejo, J. and Quagliarello, V.J. (2003) Complicated Left Sided Native Valve Endocarditis in Adults: Risk Classification for Mortality. JAMA, 289, 1933-1940. http://dx.doi.org/10.1001/jama.289.15.1933

[22] Aksoy, O., Sexton, D.J., Wang, A., Pappas, P.A., Kourany, W., Chu, V., et al. (2007) Early Surgery in Patients with Infective Endocarditis: A Propensity Score Analysis. Clinical Infectious Diseases, 44, 364-372. http://dx.doi.org/10.1086/510583

[23] Agnihotri, A.K., McGiffin, D.C., Galbraith, A.J. and O’Brien, M.F. (1995) The Prevalence of Infective Endocarditis after Aortic Valve Replacement. The Journal of Thoracic and Cardiovascular Surgery, 110, 1708-1720.

[24] Olaison, L., Hogevik, H., Myken, P., Oden, A. and Alestig, K. (1996) Early Surgery in Infective Endocarditis. QJM, 89, 267-278. http://dx.doi.org/10.1093/qjmed/89.4.267

[25] D’Udekem, Y., David, T.E., Feindel, C.M., Armstrong, S. and Sun, Z. (1997) Long-Term Results of Surgery for Active Infective Endocarditis. European Journal Cardio-Thoracic Surgery, 11, 46-52. http://dx.doi.org/10.1016/S1010-7940(96)01020-2

[26] Chastre, J. and Trouillet, J.L. (1995) Early Infective Endocarditis on Prosthetic Valves. European Heart Journal, 16, 32-38. http://dx.doi.org/10.1093/eurheartj/16.suppl_B.32

[27] Wolff, M., Witchitz, S., Chastang, C., Régnier, B. and Vachon, F. (1995) Prosthetic Valve Endocarditis in the ICU. Prognostic Factors of Overall Survival in a Series of 122 Cases and Consequences for Treatment Decision. Chest, 108, 688-694. http://dx.doi.org/10.1378/chest.108.3.688

[28] Aranki, S.F., Adams, D.H., Rizzo, R.J., Couper, G.S., Sullivan, T.E., Collins Jr., J.J. and Cohn, L.H. (1995) Determinants of Early Mortality and Late Survival in Mitral Valve Endocarditis. Circulation, 92, 143-149. http://dx.doi.org/10.1161/01.CIR.92.9.143

[29] Verheul, H.A., van den Brink, R.B., van Vreeland, T., Moulijn, A.C., Düren, D.R. and Dunning, A.J. (1993) Effects of Changes in Management of Active Infective Endocarditis on Outcome in a 25-Year Period. The American Journal of Cardiology, 72, 682-687. http://dx.doi.org/10.1016/0002-9149(93)90885-G

[30] Delahaye, J.P., Malquarti, V., Sara Darian, W., et al. (1987) Pronostic de l'endocardite infectieuse opérée. Archives des Maladies du Coeur et des Vaisseaux, 80, 302-309.

[31] Witchitz, S., Reidiboym, M., Bouvet, E., Wolff, M. and Vachon, F. (1986) Evolution des facteurs pronostiques de l'endocardite infectieuse sur une période de 16 ans à propos de 471 observations. Archives des Maladies du Coeur et des Vaisseaux, 85, 959-965.

[32] Dickerman, S.A., Abrutyn, E., Barsic, B., Bouza, E., Cecchi, E., Moreno, A., et al. (2007) The Relationship between the Initiation of Antimicrobial Therapy and the Incidence of Stroke in Infective Endocarditis: An Analysis from the ICE Prospective Cohort Study (ICE-PCS). American Heart Journal, 154, 1086-1094. http://dx.doi.org/10.1016/j.ahj.2007.07.023

[33] Prendergast, B.D. (2006) The Changing Face of Infective Endocarditis. Heart, 92, 879-885. http://dx.doi.org/10.1136/hrt.2005.067256

[34] Angstwurm, K., Borges, A.C., Halle, E., Schielke, E., Einhäupl, K.M. and Weber, J.R. (2004) Timing the Valve Replacement in Infective Endocarditis Involving the Brain. Journal of Neurology, 251, 1220-1226. http://dx.doi.org/10.1007/s00415-004-0517-x

[35] Acar, C. (2007) Early Surgery in Mitral Valve Endocarditis: It Is Sometimes Too Early. European Journal CardioThoracic Surgery, 32, 947. http://dx.doi.org/10.1016/j.ejcts.2007.08.020

[36] Kerchove, L., Vanoverschelde, J.L., Poncelet, A., Glineur, D., Rubay, J., Zech, F., Noirhomme, P. and El Khoury, G. (2007) Reconstructive Surgery in Active Mitral Valve Endocarditis: Feasibility, Safety and Durability. European Journal Cardio-Thoracic Surgery, 31, 592-599. http://dx.doi.org/10.1016/j.ejcts.2007.01.002

[37] Thuny, F., Beurtheret, S., Gariboldi, V., Mancini, J., Avierinos, J.F., Riberi, A., et al. (2008) Outcome after Surgical Treatment Performed within the First Week of Antimicrobial Therapy during Infective Endocarditis: A Prospective Study. Archives of Cardiovascular Diseases, 101, 687-695. 
[38] Delay, D., Pellerin, M., Carrier, M., Marchand, R., Auger, P., Perrault, L.P., Hébert, Y., Cartier, R., Pagé, P. and Pelletier, L.C. (2000) Immediate and Long Term Results of Valve Replacement for Native and Prosthetic Valve Endocarditis. The Annals of Thoracic Surgery, 70, 1219-1223. http://dx.doi.org/10.1016/S0003-4975(00)01887-7

[39] Iung, B., Rousseau-Paziaud, J., Cormier, B., Garbarz, E., Fondard, O., Brochet, E., Acar, C., et al. (2004) Contemporary Results of Mitral Valve Repair for Infective Endocarditis. Journal of the American College of Cardiology, 43, 386-392. http://dx.doi.org/10.1016/j.jacc.2003.09.034

[40] Young, J.B., Welton, D.E., Raizner, A.E., et al. (1979) Surgery in Active Endocarditis. Circulation, 60, 177-181. http://dx.doi.org/10.1161/01.CIR.60.2.77

[41] Castillo, J.C., Anguita, M.P., Ramírez, A., Siles, J.R., Torres, F., Mesa, D., et al. (2000) Long Term Outcome of Infective Endocarditis in Patients Who Were Not Drug Addicts: A 10 Year Study. Heart, 83, 525-530. http://dx.doi.org/10.1136/heart.83.5.525

[42] Michel, P.L., Lung, B., Drissi, F., Dadez, E., Cormier, B., Acar, C., et al. (1994) La chirurgie mitrale conservatrice dans le traitement de l'insuffisance mitrale infectieuse. Archives des Maladies du Coeur et des Vaisseaux, 87, 349-355.

[43] Mullany, C.J., Chua, Y.L., Schaff, H.V., Steckelberg, J.M., Ilstrup, D.M., Orszulak, T.A., et al. (1995) Early and Late Survival after Surgical Treatment of Culture Positive Active Endocarditis. Mayo Clinic Proceedings, 70, 517-525. http://dx.doi.org/10.4065/70.6.517

\section{Submit or recommend next manuscript to SCIRP and we will provide best service for you:}

Accepting pre-submission inquiries through Email, Facebook, LinkedIn, Twitter, etc. A wide selection of journals (inclusive of 9 subjects, more than 200 journals)

Providing 24-hour high-quality service

User-friendly online submission system

Fair and swift peer-review system

Efficient typesetting and proofreading procedure

Display of the result of downloads and visits, as well as the number of cited articles

Maximum dissemination of your research work

Submit your manuscript at: http://papersubmission.scirp.org/ 